\title{
STUDYING INFORMATION \\ TECHNOLOGY IN ORGANIZATIONS: \\ RESEARCH APPROACHES AND ASSUMPTIONS
}

\author{
by \\ Wanda Orlikowski \\ Jack J. Baroudi
}




\title{
STUDYING INFORMATION TECHNOLOGY IN ORGANIZATIONS: RESEARCH APPROACHES AND ASSUMPTIONS
}

\author{
by \\ Wanda Orlikowski \\ Sloan School of Management(E53-329) \\ Massachusetts Institute of Technology \\ 50 Memorial Drive \\ Cambridge, MA 02139 \\ and \\ Jack J. Baroudi \\ Leonard N. Stern School of Business \\ Information Systems Department \\ New York University \\ 100 Trinity Place \\ New York, NY 10006
}

February 1990
Center for Research on Information Systems
Information Systems Department
Leonard N. Stern School of Business
New York University

\section{Working Paper Series}

STERN IS-90-4

An earlier draft of this paper was presented at the Academy of Management Meeting in Anaheim, CA, August 1988 
Center for Digital Economy Research

Stern School of Business

Working Paper IS-90-04 


\title{
Studying Information Technology in Organizations: Research Approaches and Assumptions
}

\begin{abstract}
We examined 155 behavioral information systems research articles published from 1983-1988 and found that while this research is not rooted in a single overarching theoretical perspective it does exhibit a single set of philosophical assumptions about the the nature of valid evidence and the phenomena of interest to information systems researchers. We argue in this paper that these philosophical assumptions draw on the natural science tradition, and hence may not always be appropriate for inquiry into the relationships between information technology and people or organizations. In particular, we suggest that the development and use of information technology within organizations is inherently processual and contextual, and that these characteristics are not always adequately captured by the philosophical assumptions prevalent in information systems research. Positing social process as central to information systems phenomena asserts the importance of studying the ongoing interactions among people, information technology and organizations, as these are situated historically and contextually.

We argue in this paper that the dominant research perspective in information systems research is not well-equipped to deal with situated interactions over time, and propose additional research philosophies to augment the one currently favored by behavioral information systems researchers. We outline the features of such additional research perspectives, the interpretive and the critical, providing empirical examples to illustrate how and when they may be useful. We conclude that multiple research perspectives can usefully be employed within the information systems community to enrich understanding of behavioral information systems phenomena.
\end{abstract}


Center for Digital Economy Research

Stern School of Business

Working Paper IS-90-04 


\section{INTRODUCTION}

One of the most pronounced features of contemporary social research - and by this we mean those disciplines concerned with human phenomena (individual and collective) such as psychology, sociology, anthropology and their applied fields of administrative science, education, industrial psychology and industrial sociology - is the great range of research perspectives or paradigms that operate concurrently [Astley \& Van de Ven 1983; Burrell \& Morgan 1979; Morgan 1980, 1983; Pfeffer 1982]. These disciplines are marked by a plethora of "schools of thought" each with its own metatheoretic assumptions, research methodologies and adherents. Given the complex and indeterminate nature of the social phenomena studied within these fields, the existence of a plurality of perspectives allows the exploration of diverse questions and hence adds breadth as well as depth to the knowledge generated. In behavioral information systems research however, such a diversity of research schools is not evident. ${ }^{1}$

In this paper we suggest that while no clear, collective theory binds the information systems discipline, there appears to be an implicit agreement among behavioral information systems researchers about the underlying nature of the phenomena to be investigated and what constitute appropriate research methods. In the next section we provide evidence for such a collective research tradition, and why we believe such a single philosophy towards studying behavioral information systems phenomena can be limiting. In the following two sections we explore two other philosophical traditions which we believe can supplement and enrich behavioral information systems research endeavors. We conclude with some general recommendations for the information systems community.

\section{A DOMINANT PERSPECTIVE IN BEHAVIORAL INFORMATION SYSTEMS RESEARCH}

Much recent self-reflection of the information systems discipline has involved a discussion of paradigms, ${ }^{2}$ and the status of information systems research vis-á-vis the norms of what constitutes a scientific discipline [Benbasat 1985; Culnan 1986, 1987; Culnan \& Swanson 1986; Hamilton \& Ives 1982; Keen 1980; Klein \& Welke 1982; Weber 1984]. In all the above studies the focus has been on identifying and articulating theoretical commonalities or topic synthesis.

\footnotetext{
${ }^{1}$ The body of information systems research concerned with studying the interaction of information technology and humans at both micro and macro levels of analysis we shall refer to as "behavioral information systems research."

2 The significance of paradigms for scientific activity has influenced much work in the history and philosophy of science [Bernstein 1978, 1985; Hacking 1981; Kuhn 1970; Ryan 1970, 1973]. One definition given by Kuhn [1970:10] is that a paradigm includes "... law, theory, application, and instrumentation together ... [providing] models from which spring coherent traditions of scientific research."
} 
We argue, following Chua [1986] and Webster \& Starbuck [1988] however, that another indicator of a research tradition is the extent to which there exists a set of dominant philosophical assumptions or a world view that informs the work of the researchers in a discipline. Chua [1986:602] suggests that a community of scientists share “.... a constellation of beliefs, values, and techniques" and that these beliefs "... circumscribe definitions of 'worthwhile problems' and 'acceptable scientific evidence." In the following section we show that the discipline of behavioral information systems research has indeed been guided by a dominant world view, and while this consensus has advanced research into certain kinds of information systems phenomena, we believe that it has also neglected others. As a consequence, this exclusive approach to information systems phenomena has "... limited the type of problems studied, the use of research methods, and the possible research insights that could be obtained" [Chua 1986:602].

\section{Evidence of a Dominant Perspective in Behavioral Information Systems Research}

In a recent assessment of the published information systems literature, Culnan's [1986] bibliographic citation analysis of information systems research publications (1972 to 1982), established nine distinct (and disparate) research areas in the information systems community. Further, Culnan [1987], again employing bibliographic citation analysis, identified five intellectual subfields within current information systems research, suggesting " .... that while MIS is still pre-paradigmatic, it has made progress, if one accepts the argument that MIS, like all social sciences, is a multiple paradigm discipline" [1987:347].

In this paper we wish to argue that while there may be no theoretical or topic congruence among information systems researchers, there is a consistent philosophical world view that underlies much of the activity constituting the field of behavioral information systems research, and that binds information systems researchers together. ${ }^{3}$ To explore this assertion we examined the behavioral information systems literature published from January 1983 to May 1988 in four major information systems outlets. These sources were: Communications of the ACM, Proceedings of the International Conference on Information Systems, Management Science, and MIS Quarterly. ${ }^{4}$ Figure one displays the distribution of behavioral information systems research

\footnotetext{
${ }^{3}$ We specifically limit our remarks to behavioral information systems research, as we believe this is the subdiscipline that can most benefit from multiple philosophical approaches.

4 We only examined mainstream American journals, as we believe that these represent the largest forum for publishing behavioral information systems research, and currently inform the majority of behavioral information system researchers. We acknowledge that by excluding the European journals we have limited the survey's exposure to nontraditional research work.
} 
published across these four sources. As we are concerned with research conduct, we excluded any conceptual or framework articles from consideration. A total of 155 empirical research articles were included in this analysis.

-----Insert figure one here-----

The research articles were categorized along several different dimensions. The first used Culnan's [1987] five topic-oriented research categories. These topic categories include research foundations, macro approaches to information systems, micro approaches to information systems, information systems management, and information systems curriculum. Culnan's foundation and curriculum categories were discarded as we were only concerned with empirical research. The distribution of articles by Culnan's categories is presented in figure two. This data confirms Culnan's $[1986,1987]$ conclusions in that, as in her studies, there does not appear to be one dominant theoretical paradigm, but rather several different and distinct streams of research.

-----Insert figure two here-----

To explore the extent to which a dominant set of assumptions informs behavioral information systems research, we analyzed the sample in three different ways. The first is by research design, the second by time frame of the study, and finally by epistemology. A discussion of the consequences of our findings is deferred to the following section. Figure three presents the first breakdown showing the frequency of the various research designs. The three primary research designs which emerged from this analysis are case studies (13.5\%), lab experiments (27.1\%) and surveys (49.1\%). These three designs account for almost $90 \%$ of the studies. Surveys, however, were clearly the dominant research method in this sample.

-----Insert figure three here-----

The data was then analyzed by time period of the study. Four different categories were sufficient to classify the data. Studies were one shot cross-sectional, cross-sectional over multiple time periods, longitudinal, or involve process tracing such as protocol analysis. Protocol analyses were classified separately as they do not neatly fit into the other categories. They employ continuous data collection, but are not truly longitudinal as the trace is typically conducted over a single discrete event - such as a meeting or problem-solving exercise - lasting a short period of time such as a few hours. We distinguished between multiple time period cross-sectional studies 
and longitudinal ones; the former employ some measure(s) administered at several time intervals, providing many discrete snap shots of the phenomenon; the latter are continuous studies where the researcher engages with the phenomenon over an uninterrupted period of time, such as a few months or years, and typically focuses on issues of process. The breakdown of articles by time period is presented in figure four. Static, one shot cross-sectional studies are clearly the predominant form of research in information systems. These studies account for $90.3 \%$ of the articles in our sample. Longitudinal and multiple time period studies account for only $4.5 \%$ and $3.9 \%$ of the sample, respectively.

-----Insert figure four here-----

Articles were finally examined for the underlying epistemology which guided the research. We followed Chua's [1986] classification of research epistemologies into positivist, interpretive, or critical studies. We found it useful, however, to distinguish within the positivist studies those that were purely descriptive. In descriptive studies there is no theoretical grounding or interpretation of the phenomena, rather the studies are straightforward "factual" accounts of events which are viewed as illustrating some issue of interest to the researchers. Little theory building or theory testing is possible under such conditions. Descriptive articles typically were case studies and used simple descriptive statistics (frequencies and percentages).

Positivist studies are premised on a priori fixed relationships within the phenomena which are studied with structured instrumentation. Such studies serve primarily to test theory. Interpretive studies explicitly adopt a nondeterministic perspective, attempting to explore the phenomena of interest in its natural setting, deliberately not imposing any a priori understanding on it. Critical studies aim, through the exposure of deep-seated structural problems, to critique the status quo and remove contradictions from organizations and society. Such studies are concerned with evaluation, as well as with description and explanation. Figure five shows the breakdown of articles by epistemology. Positivism is clearly the dominant epistemology accounting for $96.8 \%$ of the studies (descriptive studies make up $23.9 \%$ of this subtotal), with interpretive studies representing only $3.2 \%$ of the sample, and critical studies not being represented at all.

-----Insert figure five here-----

The figures collectively show that while no one theoretical paradigm dominates behavioral information systems research, there clearly is a dominant set of assumptions about what constitutes acceptable behavioral information systems research. This set of assumptions that 
appears to influence much of the published behavioral information systems research is primarily survey or laboratory oriented and investigates phenomena within a single cross-section or slice of time. It is not clear, however, that researchers consciously make choices about these assumptions, rather it appears that these are largely taken for granted, and in this unreflectiveness, the single dominant world view may be limiting the questions asked and the insights gained in behavioral information systems research.

\section{Consequences of a Dominant Research Perspective in Behavioral Information Systems Research}

Much of the behavioral information systems research being conducted today is concerned with the ongoing relationship existing between information technology and individuals and organizations. Implementation studies for example, [Alavi \& Henderson 1981; Franz \& Robey 1984; Ginzberg 1981; Lucas 1981; Markus 1983], are concerned with how, over time, we successfully introduce information technology into organizations. Systems development researchers [Bostrom \& Heinen 1977a, 1977b; Mumford \& Weir 1979] are concerned with how we build systems that are efficient and effective and that also increase users' job satisfaction. There is a large and growing interest in computer-mediated support of communication, collaborative work, and group decision-making [Culnan \& Markus 1987; Poole \& DeSancits 1989; Rice \& Associates 1984; Sproull \& Kiesler 1986; Suchman 1983]. Information systems personnel researchers [Bartol 1983; Baroudi 1985; Ivancevich et al. 1983; Weiss 1983] are concerned with understanding the processes which result in job dissatisfaction, turnover, and stress for systems builders. Other researchers have focused on the power shifts generated by technology and technological dependence [Lucas 1984; Markus \& Bjørn-Anderson 1987; Saunders \& Scamell 1986]. Many studies have been conducted into the effects of computerization on job skills and employment levels [see the review of studies by Attewell \& Rule 1984]. And the "impacts school" of information systems research examines the implications (individual, group, organizational, and societal) of widespread use of information technology [Bjørn-Andersen \& Pederson 1980; Danziger et al. 1982; Kling 1978, 1980; Kling \& Iacono 1984; Laudon 1974; Olson \& Primps 1984; Turner 1984; Zuboff 1988]. These are only a sampling of topics that one can find under investigation yet all share a common thread. All are concerned with the social processes surrounding the introduction, creation, use/disuse of information technology, as portrayed by Kling \& Scacchi's [1982] metaphor of the ongoing "web of computing."

To date, as evidenced by the analysis above, much behavioral information systems research reflects a positivistic orientation, a research tradition that has its roots in the natural sciences. 
However as we will show, adopting a positivistic research approach to information systems phenomena implies focusing on only certain aspects of the information systems phenomena. An exclusive view is always only a partial view, and the dominance of positivism has limited what and how we have studied information systems in organizations. This has implications not only for the development of theory and our understanding of information systems phenomena, but also for the practice of information systems work. The findings of information systems research filter into the practitioner community and are used as prescriptions for action. Restricted and partial research thus has far-reaching consequences.

Through this paper we wish to encourage a greater awareness and understanding of the diversity of assumptions that underlie social research. In particular, we want to draw attention to the inadvertent restrictions we impose on our research when we unquestioningly accept the assumptions of research of the dominant perspectives. We wish to argue there are a number of alternative philosophical perspectives that may be particularly useful in helping us to study the phenomena which absorb behavioral information system researchers. In the following we explore this claim in more detail by examining the various research perspectives with which social science researchers may approach their phenomena of interest. In discussing these various research approaches we draw on Chua's [1986] classification of the assumptions constituting the philosophical stances that researchers adopt towards the world and their work. Chua [1986:604] articulates three sets of beliefs that "... delineate a way of seeing and researching the world," that is, (i) beliefs about the phenomenon or "object" of study, (ii) beliefs about the notion of knowledge, and (iii) beliefs about the relationship between knowledge and the empirical world (see figure 6). Various positions on these three sets of beliefs can be seen to constitute the distinctive research perspectives or world views that social science researchers have adopted towards their research.

-----Insert figure six here-----

\section{(i) Beliefs about Physical and Social Reality:}

Ontological beliefs have to do with the essence of phenomena under investigation, that is, whether the empirical world is assumed to be objective and hence independent of humans, or subjective and hence having existence only through the action of humans in creating and recreating it. Then there are beliefs about human rationality, which deal with the intentions ascribed by various researcher to the humans they study. For example, the discipline of economics is premised on beliefs about humans as utility maximizing and as having limited access to information. Finally, there are beliefs about social relations, about how people interact 
in organizations, groups, and society. For example, researchers may believe social interactions to be stable and orderly in general, or they may believe them to be primarily dynamic and conflictual.

\section{(ii) Beliefs about Knowledge}

Epistemological assumptions concern the criteria by which valid knowledge about a phenomenon may be constructed and evaluated. For example, the positivist world view asserts that a theory is true only if it is repeatedly not falsified by empirical events [Chua 1986:604]. Methodological assumptions indicate which research methods and techniques are considered appropriate for the gathering of valid empirical evidence. Which methods are considered appropriate clearly depend on how the veracity of a theory is established. Positivist researchers, for example, believe that large-scale sample surveys and controlled laboratory experiments are suitable research methods as they allow researchers a certain amount of control over data collection and analysis through manipulation of research design parameters and statistical procedures.

\section{(iii) Beliefs about the Relationship between Knowledge and the Empirical World}

These beliefs concern the role of theory in the world of practice, and reflect the values and intentions researchers bring to their work. That is, what researchers believe is appropriate to accomplish with their research work, and what they intend to achieve with a given research study. Some researchers pursue their research interests and certain kinds of theory to provide technical answers to specialized problems. Other researchers pursue theory which they hope will improve the social relations of organizations, or eliminate social inequities.

The following sections explore the underlying assumptions of three research philosophies that have been used to conduct social science research, including information systems research: the positivist, interpretive, and critical philosophies. Each alternative philosophy has different strengths and weaknesses, highlighting not only different phenomena but also different aspects of phenomena. We will discuss each alternative in turn, outlining the distinctive positions each assumes on the three sets of beliefs articulated in figure six. While none of these alternatives is a panacea that will assuage the limitations currently frustrating behavioral information systems research endeavors [Attewell \& Rule 1984; Weick 1984], we believe that work conducted across this spectrum of philosophies will enhance and expand our collective research insight, as the exclusive dominance of a single research philosophy cannot. 


\section{THE POSITIVIST PHILOSOPHY OF BEHAVIORAL INFORMATION SYSTEMS RESEARCH}

As indicated above, a positivist research perspective is dominant in behavioral information systems research, a dominance which reflects the status of much of Western science. With roots in logical positivism, this perspective reflects the precepts informing the study of natural phenomena [Lincoln \& Guba 1985:36]: 5

- The phenomenon of interest is single, tangible and fragmentable, and there is a unique, best description of any chosen aspect of the phenomenon;

- The researcher and the object of inquiry are independent, and there is a sharp demarcation between observation reports and theory statements;

- Nomothetic statements (law-like generalizations that are independent of time and context) are possible, which implies that scientific concepts are precise, having fixed and invariant meanings;

- There exist real, uni-directional cause-effect relationships that are capable of being identified and tested via hypothetic-deductive logic and analysis;

- Inquiry is value-free.

A number of commentators have indicated that the application of these precepts to research on social phenomena is problematic [Evered \& Louis 1981; Galliers \& Land 1987; Lincoln \& Guba 1985; Morgan 1980; Morgan \& Smircich 1980; Weick 1985]. Indeed, many researchers practising positivist research would agree that some of these precepts are ideals that are typically compromised in the exigencies of daily research activity. In the following we explore some of the assumptions underlying the positivist precepts.

\section{Beliefs about Physical and Social Reality}

Ontologically, positivist informations systems researchers assume an objective physical and social world that exists independently of humans, and whose nature can be unproblematically apprehended, characterized, and measured. For example, organizations are understood to have form and a reality beyond the actions of their members. The role of the researcher is to "discover" the objective physical and social reality by crafting precise instruments that will detect and gauge those dimensions of reality that interest the researcher. It is assumed, explicitly or

\footnotetext{
${ }^{5}$ Recent work in the post-empiricist philosophy of science [Bernstein 1985; Bhaskar 1978] has begun to question the validity of these assumptions for the practice of natural science. To the extent that the positivist dogma lose their currency among mainstream natural scientists we should begin to see a growing interest among social scientists for additional research perspectives of the sort discussed in this paper.
} 
implicitly, that there is a one-to-one correspondence between the constructs of a researcher's model and the "objects" or "features" of interest in the world. Understanding phenomena is a problem of measurement, of constructing an appropriate and accurate set of instruments to capture the essence of the phenomenon. The researcher herself is seen to play a passive, neutral role in this investigation, and does not intervene in the phenomenon of interest. For example, when researchers investigate the relationship between information technology and organizational structure, they assume structure to be objective and hence capable of being represented via a number of researcher-devised constructs and measures such as: span of control, division of labor, centralization, formalization, and hierarchical levels.

Most researchers subscribing to the positivist perspective assume that human action is intentional and rational, or at the least boundedly rational. The assumption about social reality is that humans interact in relatively stable and orderly ways, and that conflict and contradiction are not endemic to organizations or society. When conflict does occur, its effect is seen to be dysfunctional to the system (organization, society, etc.) and hence as something to be suppressed or overcome. Conflict is seen as serving to reveal some discrepancy in the system, as a symptom of some problem which can then be corrected, hence preventing some potentially disruptive system breakdown. The positivist research perspective tends to disregard the historical context of phenomena, hence such research is rooted in the status quo.

\section{Beliefs about Knowledge}

With respect to knowledge, the epistemological belief of the positivist perspective is concerned with the empirical testability of theories, whether this requires theories to be "verified" or "falsified." This belief, in what is known as the hypothetico-deductive account of scientific explanation, has two consequences [Chua 1986:607]:

- A search for universal laws or principles from which lower-level hypotheses may be deduced. Positivist researchers work in a deductive manner to discover unilateral causal relationships, that are the basis of generalized knowledge; that is, that can predict patterns of behavior across situations [Putnam 1983:41].

- A tight coupling among explanation, prediction, and technical control. If an event or action is only explained when it can be deduced from certain principles and premises, then knowing the principles and premises beforehand enables prediction and control of the event or action.

The search for general connections between information technology and changing environmental conditions or organizational forms - as for example, evident in the contingency or transaction 
costs theories - assumes that the empirical world is largely characterized by knowable, constant relationships. To support such an epistemological belief, the positivist research perspective endorses a number of "appropriate" research methodologies. The belief here is that following these sanctioned methodologies is the only way in which valid knowledge can be obtained, what Gibbons [1987:1] refers to as "methodological monism." He goes on to characterize the epistemological beliefs of this mode of inquiry as one in which units of data are assumed to be identifiable (for example, subjective attitudes) and assumed to exist independently of the method used to reveal or measure them. Sample surveys and controlled experiments are the primary data collection techniques, and inferential statistics is the data analysis method used to "discover" causal laws. The validity and reliability of identifying and measuring instruments are crucial, as are researcher detachment from the research process, random assignment of subjects, and control over confounding influences. The concepts populating the language of the positivist research philosophy cannot reflect the everyday language usage of the study participants as these are considered too ambiguous and subjective. Consequently, the concepts of positivist science "... must be redefined in order to eliminate the evaluative dimension and to ensure uniformity of measurement among researchers" [Gibbons 1987:1].

\section{Beliefs about the Relationship between Theory and Practice}

The positivist research approach towards the relationship between theory and practice is that the researcher is independent of the phenomena being studied, and hence assumes a value-neutral stance. As an impartial observer, the researcher can objectively evaluate efficient and effective actions or processes, but should not get involved in moral judgements or subjective opinion. That is, researchers can comment on means, but not ends. However, as Weber [1947] recognized, the very distinction between fact and value is itself a value judgement. This is typically not recognized, or at least, not acknowledged by researchers working out of the positivist perspective.

Another issue not recognized by positivist researchers is the extent to which they are inherently implicated in their research subject matter. This pertains to the role played by social research in practice. Unlike the natural sciences where it can be argued that there exists an independence between researcher and phenomenon of study, the same assertion cannot be made for the social sciences. While the results of natural science do not impinge on and change the nature of the phenomena studied, the results of social science do enter into the discourse of everyday human reality, and clearly can and do transform the nature of these phenomena. As Giddens [1987:19] notes, in the social sciences, unlike in natural science, there is no way of keeping the concepts, theories, and findings of the researchers "... free from appropriation by lay actors." Clearly 
behavioral information systems research enters into the very constitution of the phenomena it studies, in a manner not available to natural science. ${ }^{6}$ Indeed, a major goal of information systems research is to have an impact on information systems practice, that is, the findings of information systems research are intended to inform and improve the development and use of information systems in organizations. There clearly is a reciprocal and reflexive relationship between information systems research and social reality; the two are not independent of each other. In the light of this, claims of objectivity and value-neutrality in behavioral information systems research are misleading.

\section{Positivist Research Philosophy: Assessment}

A number of commentators have discussed the limitations of the positivist research perspective [Burrell \& Morgan 1979; Chua 1986; Lincoln \& Guba 1985; Morgan 1983; Mumford et al. 1985; Putnam 1983; Weick 1984]. We will just mention two here. The quest for universal laws leads to a disregard for historical and contextual conditions as possible triggers of events or influences on human action. The design and use of information technology in organizations however, is inevitably embedded in social contexts, marked by time, locale, politics, and culture. Neglecting these influences can only reveal an incomplete picture of information systems phenomena. Likewise, the positivist aim to explain and predict external reality implies that people are not active makers of their physical and social reality. Positivistic research techniques encourage deterministic explanations of phenomena, in that these explanations emerge from interactions between the researcher and his subjects, where the researcher, by definition, dominates the relationship. In the search for causal relations the positivist researcher focuses on the validity and control of the research procedures, and hence adopts a predefined and circumscribed stance towards the phenomenon being investigated. Such a posture is not conducive to the discovery and understanding of non-deterministic and reciprocal relationships. Laboratory subjects and survey respondents act and react mechanically to the research stimulus. Rowan [1973:210] notes: "Research can only discover one-sided things if it insists on setting up one-sided relationships ... You only get answers to those questions you are asking." Only if we have strong reason to suspect that the relationships underlying our phenomena of interest information technology and human life - are determinate and one-dimensionally causal, can we utilize such positivist techniques with confidence. As Markus \& Robey [1988] elucidate, there is no reason to suspect that this is the case with information technology and human life.

\footnotetext{
6 as a cursory view of some of the primary behavioral information systems research areas reveals: systems development and implementation, information management, decision and expert support systems, end-user computing, information systems personnel issues, computer-mediated tasks, computer-supported cooperative work, and the strategic deployment of information technology.
} 
However, despite the limitations, this stream of research has institutionalized certain criteria of validity, rigor, and replicability in the conduct of scientific research. It has enforced standards of quality in empirical research, and has sought to build a tradition of cumulative knowledge across the various disciplines in which it is practised. This philosophical perspective may well be suited to answering certain kinds of research questions. Difficulties arise, however, when proponents of this research perspective do not admit the validity of any other philosophical stance, precluding the possibility of different forms of knowledge, and different assumptions about reality. Such orthodoxy is restrictive, for as we discuss below, some aspects of phenomena cannot be appropriately represented in the positivist world view and hence to attempt to understand them at all requires adopting a different philosophical perspective. In the following two sections, we examine two alternatives to the positivist research philosophy, the interpretive and the critical.

\section{THE INTERPRETIVE PHILOSOPHY OF BEHAVIORAL INFORMATION SYSTEMS RESEARCH}

In this section we focus on the premises of the interpretive perspective, which is receiving increased attention and popularity in many social science fields (organizational studies, political science, sociology, marketing, education, and social psychology). A fundamental distinction between the interpretive and positivist world views is the former's primary presumption of social constructionism. Interpretivism asserts that reality, as well as our knowledge thereof, are social products and hence incapable of being understood independently of the social actors (including the researchers) that construct and make sense of that reality. The world is not conceived of as a fixed constitution of objects, but rather as " ... an emergent social process - as an extension of human consciousness and subjective experience” [Burrell \& Morgan 1979:253]. The aim of all interpretivist research is to understand how members of a social group, through their participation in social processes, enact their particular realities and endow them with meaning, and to show how these meanings, beliefs and intentions of the members help to constitute their social action. The interpretive perspective attempts " $\ldots$ to understand the intersubjective meanings embedded in social life ... [and] to explain why people act the way they do" [Gibbons 1987:3].

\section{Beliefs about Physical and Social Reality}

Ontologically, the interpretive perspective emphasizes the importance of subjective meanings and social-political as well as symbolic action in the processes through which humans construct and reconstruct their reality [Morgan 1983:396]. For example, this tradition does not presume that 
organizational structure, or social relations are objectively known and unproblematic, but attempts to understand how and why individuals, through their socialization into, interaction with, and participation in, a social world, give it a certain meaning. Meaning and intentional descriptions are important not merely because they reveal subjects' states of mind which can be correlated with external behavior, but because they are constitutive of those behaviors. Fay [1987:86] notes "It is only because actors share certain basic conceptions that there can be certain types of social action. For example, the social practice of the market-place can occur given the shared constitutive meanings of (say) some conceptions of private property, the notion that in the exchange of goods and services some form of maximizing one's resources is the appropriate course of action, some idea of being an independent agent, etc."

Ontologically, interpretive informations systems research assumes that the social world (that is, social relations, organizations, division of labor) are not "given." Rather, the social world is produced and reinforced by humans through their action and interaction. Organizations, groups, social systems do not exist apart from humans, and hence cannot be apprehended, characterized, and measured in some objective or universal way. Unlike the premises of the positivist perspective where researchers are presumed to "discover" an objective social reality, interpretive researchers believe that social reality can only be interpreted. While interpretive researchers share with the positivist philosophy a belief in relatively orderly interaction, this regularity is not attributed to functional needs of the social system, but to the shared norms and interests that bind humans together. While not positing endemic contradiction in social relations, ${ }^{7}$ interpretive researchers recognize that as meanings are formed, transferred, and used, they are also negotiated, and hence that interpretations of reality may shift over time as circumstances and constituents change.

\section{Beliefs about Knowledge}

The interpretive philosophy is premised on the epistemological belief that "... social process is not captured in hypothetical deductions, covariances, and degrees of freedom. Instead, understanding social process involves getting inside the world of those generating it" [Rosen, in press]. This philosophy challenges the positivist perspective's insistence of a disjuncture between everyday social practices and the language used to describe them. The interpretive position asserts that the language humans use to describe social practices constitute those practices. Thus, understanding social reality requires understanding how practices and meanings are formed and informed by the language and tacit norms shared by humans working towards

${ }^{7}$ as does the critical philosophy (see following section). 
some common goal. Interpretive researchers construct interpretations or explanations that account for the way that subjective meanings are created and sustained in a particular setting [Putnam 1983:41]. Such explanations are causal but not in the positivists' uni-directional sense, nor are they sought for the same purpose. Interpretive researchers posit circular or reciprocally interacting models of causality, with the intention of understanding actors' views of their social world.

The research methods appropriate to generating valid interpretive knowledge are field studies as these examine humans within their social settings. Following on the ontological belief that reality is socially constructed, the interpretive researcher avoids imposing external categories on a phenomenon. Instead of the researcher coming to the field with a well-defined set of constructs and instruments with which to measure the social reality, the interpretive researcher attempts to derive his or her constructs from the field by in-depth examination of and exposure to the phenomenon of interest. The categories that emerge out of this approach are intended to closely couple those categories used by the study's participants.

The underlying premise of the interpretive researcher is "... that individuals act towards things on the basis of the meanings that things have for them, that meanings arise out of social interaction and that meanings are developed and modified through an interpretive process" [Boland 1979:260]. In this sense of attempting to understand meaning, positivist approaches are not useful. Rowan [1973:216] notes that in positivist research " ... we are talking to 'processed people' in the sense that they can only answer in terms of our questions and our categories." In contrast, interpretive techniques allow participants to use their own words and to draw on their own concepts and experiences. The primary endeavor is to describe, analyze and understand the social world from the actors' perspective, and any rigid a priori researcher-imposed formulations of structure, function, purpose and attribution are resisted [Glaser \& Strauss 1967].

\section{Beliefs about the Relationship between Theory and Practice}

The interpretive research approach towards the relationship between theory and practice is that the researcher can never assume a value-neutral stance, and is always implicated in the phenomena being studied. The extent of researcher implication, however, is the cause of some debate within the interpretive traditions. Just as the positivist research perspective is not entirely homogeneous, with researchers differing on issues such as verifiability and researcher independence, the interpretive perspective is also differentiated. Two primary variants are recognizable, and they differ on the role of the researcher in investigating a phenomenon. Both variants recognize that human actors enact their physical and social reality and that they come to 
share a set of meanings around this reality. In the "weak" constructionist view [Weick 1979], the researcher attempts - through various data collection techniques - to understand the existing meaning systems shared by the actors, and thereby interprets their action and events in her recounting. As Fay [1987:88] puts it: “... the social scientist is redescribing an act or experience by setting it into progressively larger contexts of purpose and intelligibility, ... [and] reveals what the agents are doing by seeing what they are up to and how and why they would be up to that."

In the "strong" constructionist view, however, the researcher is not merely presumed to describe a phenomenon in the words and categories of the actors, but is presumed to enact the social reality he is studying. Re-telling the actors' story is never fully possible as the interpretive schemes of the researcher always intervene, and hence the researcher in part creates the reality he is studying through the constructs used to view the world. Astley [1985:498] writes: "The world of practice has its own 'objective' reality, but since as scientists, our only recourse to that world is through what we see and do, our knowledge is unavoidably subjective in nature. The 'facts' constituting our knowledge, are necessarily theory-dependent, since we can perceive nothing except through the knowledge structure in which perception is embedded... There is no direct access to reality unmediated by language and preconceptions."

This difference between weak and the strong constructionist positions has implications for how interpretive research relates to research conducted in the positivist mode. From the viewpoint of weak constructionism, interpretivist research is understood to complement positivist research, that is, by generating hypotheses for further investigation, and by filling-in the knowledge gaps that positivist research cannot attend to, such as the contextual exigencies, the meaning systems, and the interaction of various components of a system. The researcher chooses between positivist and interpretive approaches based on the research question and the nature of the phenomenon of interest. This argument, postulated among others by Daft \& Wiginton [1979], suggests that the positivist research approach (seen as encompassing "low variety" techniques) is not complex enough to reflect all of the inherent complexity, ambiguity, and instability of organizational systems. Invoking the principle of requisite variety, Daft \& Wiginton [1979:187] encourage the use of alternative "high variety" methodologies. They note: "If complex organizational behaviors are modelled as if they are simple, well understood, deterministic systems, or even as stochastic systems, then the resulting models will tend to be insignificant. We propose that languages of high variety are useful tools for developing models of organizations because they have sufficient scope and richness of meaning to describe organizational processes." A similar case has been argued for information systems research, that is, that the current positivist perspective has 
insufficient variety for the nature of the phenomena investigated by behavioral information systems researchers [Benbasat et al. 1987; Kaplan \& Duchon 1988; Lee 1989]. And hence a call for triangulating the use of interpretive methods with positivistic ones has been issued.

For proponents of the strong constructionist view, however, no triangulation is possible for there is no sense in which the interpretive perspective can accommodate positivistic beliefs. Interpretive research is seen to be based on essentially different philosophical assumptions to those of the positivist perspective. The role of interpretive research then, is not to complement positivist investigations, but to replace them. In this extreme view, a researcher cannot select her research perspective based on the nature of the phenomenon, for there is no way to independently assess that nature without relying on the researcher's predispositions. In choosing a research approach thus, the researcher is in fact choosing which aspects of a phenomenon she wishes to focus on. The researcher constructs the form and nature of the phenomenon through the world view he/she adopts to do the research. So that the researcher's assumptions and values are deeply embroiled in the phenomenon even in the very selection of a research approach. And if that is the case, then a researcher cannot really choose an "appropriate" research method. One is reminded of Simons' allegorical tale recounted in Weick [1979:1] of the three baseball umpires disagreeing about the task of calling balls and strikes: "The first one said, 'I calls them as they is.' The second one said, 'I calls them as I sees them.' The third and cleverest umpire said, 'They ain't nothin' till I calls them.' "'

\section{Interpretive Research Philosophy: Empirical Example}

In this section we will review a study exploring the interaction of technology in organizations which was executed using an interpretive research approach [Orlikowski 1989]. ${ }^{8}$ This should help to illustrate the characteristics and assumptions of this approach.

In this study, Orlikowski [1989] was interested in understanding how the deployment of information technology in primary business activities affected production workers. She was specifically interested in understanding how the use of information technology would change the division of labor and patterns of dependence among workers engaged in systems development work. The research site was a large consulting firm employing computer-aided software engineering (CASE) tools. Orlikowski studied several teams within the firm making sure to include teams in all the various stages of the systems lifecycle. The study employed ethnographic

8 See also Boland [1979, 1985], Boland \& Day [1982], Hirschheim, Klein \& Newman [1987], Newman \& Sabherwal [1989], and Pettigrew [1985] for interpretivist perspectives on information systems phenomena. 
techniques [Agar 1980; Van Maanen 1979, 1988] such as observation of participants, researcher interaction with and study of CASE tools, documentation review, social contact, unstructured and semi-structured interviews, and was executed over eight months full-time within the firm and in those client sites where project teams were building application systems. Orlikowski employed a theoretical framework which focused her questions and observations, however, she used no structured instrumentation, and employed no statistics to report her findings.

She attempts to understand the implications of the CASE tools for the work and workers through understanding the norms and meanings the project team members share around their work, how they interact among themselves and with the CASE tools, and how these meanings and experiences have changed since the arrival of the information technology. In her report she attempts to let the participants speak for themselves, drawing extensively on her field notes to illustrate the findings. In addition to reporting the participants experiences in their own words, Orlikowski attempts to interpret these experiences in terms of the theoretical model guiding the study. This theoretical interpretation allows her to restate the findings more generally by deriving general patterns that may be meaningful beyond the confines of the one research site.

Orlikowski found that the introduction of CASE technology had significant implications for the division of labor and relations of dependency among the project team members. In particular, she found that the deployment of CASE tools ".... triggered structural changes within the project teams, which institutionalized the existing, formalized fragmentation into technical and functional groupings..." and that this "... undermines the homogeneity of the Beta 'team' ideology by breeding subcultures and territorialism... [which] results in tension and conflict on project teams..." [p. 207].

This study has the distinctive flavor of interpretive research. Orlikowski clearly states her theoretical framework and assumptions upfront such that the reader may understand any biases or blinders she brings to the study. Second, she focuses on allowing the data speak to the reader, providing sufficient detail so that the reader may also interpret the data and determine for him or herself the accuracy of the analysis. The study is also careful to delineate the contextual conditions within which the research was conducted and the patterns of findings observed and analyzed. Orlikowski states: "How this conflict is played out across various production arenas remains open to empirical elaboration... Different outcomes will be generated across different contexts and different outcomes may be generated over time within the same context. While such outcomes can never be predicted unequivocally, we can determine the likelihood of different patterns of response based on an understanding of contexts, actors, and resources" [p. 208]. 


\section{Interpretive Research Philosophy: Assessment}

The contribution of the interpretive research philosophy is that it reveals the underlying connections among different parts of social reality, by examining the social rules and meanings that make social practices possible [Gibbons 1987:7-8]. This approach alerts us to the whole arena of social relations - the interactive, human action dimension that revolves around shared meanings, interpretations, and the construction of a cultural and social reality. It motivates investigations into the enactment of a shared, social reality through understanding human behavior from the point of view and through the interpretive schemas of the human actors themselves. In particular, social process can be usefully studied with an interpretive perspective, which is explicitly designed to capture complex, dynamic, social phenomena that are both context and time dependent.

The interpretive research philosophy, however, has been subject to criticism [Bernstein 1978; Burrell \& Morgan 1979; Fay 1987; Gibbons 1987]. Fay [1987:92] suggests four different deficiencies. First, the interpretive perspective does not examine the conditions, often external, which give rise to certain meanings and experiences. Second, research in this perspective omits to explain the unintended consequences of action, which by definition cannot be explained by reference to the intentions of the humans concerned. These unintended consequences of action are often a significant force in shaping social reality. For example, Giddens [1979, 1984], suggests that an important and typical unintended consequence is that which reinforces the actions, beliefs, power distribution, and roles of members of a group, so as to sustain the structure and purpose of that group as a whole over time. Third, the interpretive perspective does not adequately address the structural conflicts within society and organizations, and ignores the contradictions which may exist between actions, rules, and shared meanings, particularly where participants' accounts of action and intentions are inconsistent with their actual behavior. This perspective cannot discern or analyze the means by which actors may be blinkered or limited in their self-understanding and in their relation to social practices. Finally, the interpretive perspective neglects to explain historical change, that is, how a particular social order came to be what it is, and how it is likely to change over time. The interpretive perspective attempts to explain the status quo, hence it does not critique it, and indirectly serves to sustain it. Fay [1987:96] notes that this perspective "... assumes an inherent continuity in a particular society, i.e. it systematically ignores the possible structures of conflict within a society, structures which would generate change..." 


\section{THE CRITICAL PHILOSOPHY OF BEHAVIORAL INFORMATION SYSTEMS RESEARCH}

The critical philosophy can be seen to overcome at least some of the main criticisms that have been leveled at the interpretive philosophy. An important contribution of the critical research philosophy is given by its evaluative dimension. More than either the positivist or the interpretive research perspectives, the critical researcher attempts to critically evaluate the social reality under investigation. Where the other two research perspectives are content to predict or explain the status quo, the critical perspective is concerned with critiquing existing social systems and revealing any contradictions and conflicts that may inhere within their structures.

\section{Beliefs about Physical and Social Reality}

The central idea within critical philosophy is the belief that everything (be it humans, organizations or society) is historically constituted, and hence that human beings and organizations and society are not confined to existing in a particular state [Chua 1986:619]. Everything possesses an unfulfilled potentiality, and people, by recognizing these possibilities, can act to change their material and social circumstances. However, the critical perspective is quick to point out that this potentiality for acting for change is constrained, because humans become alienated from their potential by prevailing systems of economic, political, and cultural domination. Another important idea in critical philosophy is that of totality, which implies that things can never be treated as isolated elements. A particular element exists only in the context of the totality of relationships of which it is a part, and this part and the whole are bound by mutual interaction. The dialectical relationship between elements and the totality is understood to be shaped by historical and contextual conditions. Following Chua [1986:619], consider system developers. They are not isolated elements, but exist only in the context of organizations producing and using information technology, and a society investing in information technology as a form of production technology.

Social reality is understood to be produced and reproduced by humans, but also as assuming objective properties which tend to dominate human experience. Because of the dialectical understanding of elements and the whole, as well as the belief in human potentiality, the critical research philosophy emphasizes the historical development of phenomena. Social relations are not posited to be stable and orderly but in a constant state of development and change. Because elements reciprocally influence each other, contradictions arise which lead to conflict and change. Ollman [1976:57] stresses the temporal relationships of change: "With change occurring through contradiction, ... it is possible to view succeeding stages of any entity as reactions to what went 
before." Hence change must be understood in relation to the historical and contextual conditions that preceded and gave rise to it.

\section{Beliefs about Knowledge}

With respect to knowledge, the epistemological belief of the critical perspective is that knowledge is grounded in social and historical practices [Chua 1986:620]. There can be no theoryindependent collection and interpretation of evidence to conclusively prove or disprove a theory. The research methods of choice tend to be long-term historical studies, and ethnographic studies of organizational processes and structures. Quantitative data collection and analysis are used to a lesser extent. The predominance on historical analyses is compatible with the belief that a phenomenon can only be understood historically, through an analysis of "... what it has been, what it is becoming, and what it is not" [1986:621].

As with interpretive researchers, critical researchers believe they need to understand the language of the humans they are studying, an understanding that is necessarily temporally- and spatiallybound. However, critical researchers depart from their interpretive colleagues, in that they believe interpretation of the social world is not enough. The material conditions of domination need also to be understood and critiqued, and these are typically not accessible by merely asking participants, for just as fish cannot discern water (the medium of their existence), so humans typically cannot recognize the circumstances that shape and constrain them. Critical research, in addition to an explication of the interpretive schemes, social rules, and social structures of a particular group or organization, always involves a critique of these practices and relations.

\section{Beliefs about the Relationship between Theory and Practice}

The critical research philosophy towards the relationship between theory and practice is that the role of the researcher is to bring to consciousness the restrictive conditions of the status quo, thereby initiating change in the social relations and practices, and helping to eliminate the bases of alienation and domination. In this light, social research and social theory are understood as social critique. Steffy \& Grimes [1986:326] writing about critical organizational research, noted that its aim "... is to develop an organization science capable of changing organizational processes," while Benson [1983:53] observes that critical theory must be ".. reflexive, critical, and emancipatory, thus transcending alienated theorizing." The role of the critical researcher is always to go beyond mere studying and theorizing, to actively effect change in the phenomena investigated [Benson 1983]. 


\section{Critical Research Philosophy: Empirical Example}

In this section we examine a study of the interaction between information technology and organizations which was executed using a critical research approach [Smith 1988]. Reviewing such a study should help to highlight the unique characteristics of the critical perspective.

In this study, Smith [1988] was concerned with what impact the introduction of electronic point of sale (EPOS) systems in retail organizations would have on retail service workers. Working out of a critical perspective, he was interested in understanding how EPOS would influence the labor process, and in particular, the relationship between labor and management. Smith selected retail organizations based on the managerial control systems currently in place. He examined eight retail firms with established histories of Tayloristic work practices and much evidence of worker deskilling through management control systems (including technology). He contrasted these with eight other retail firms that had histories of craft work practices and which had resisted management control systems that deskill workers and hire cheaper labor.

Smith conducted extensive interviews and observations in the sixteen different retail organizations. Beyond the upfront focus on labor process issues of control and deskilling, Smith reports no formal hypotheses and employed no structured instruments or statistical inference testing. Smith draws on his field notes of interviews, observations, and documents to explain what he found and to support the conclusions he drew. These conclusions reflect the postBravermanian rejections of technological or managerial determinism [Littler \& Salaman 1982; Wood 1982] typical of contemporary labor process research. Smith suggests that the information technology represented by the EPOS systems did not change the control systems of the retail firms, but rather, that the retail organizations and in particular, the institutionalized management control systems and history of work practices shaped the use and impacts of the EPOS systems. Smith reports that firms with established Tayloristic labor relations and work practices deployed EPOS to further deskill the workers, and used the information coming out of the EPOS systems to centralized information and decision-making in the hands of fewer and more senior managers of the organizations. In these efforts, not only the workers were affected; the local retail outlet managers found that their authority and decision-making discretion had been undermined. In striking contrast, Smith found that the use of EPOS in craft retail organizations, rather than being used to centralize information and buying decisions to senior management and deskill workers, was used to provide information directly to the local managers, resulting in a greater decentralization of control and an increase in local autonomy. Smith [1988:159] concludes that EPOS (information technology) itself is "malleable," able to be deployed by managers in ways that reflect and sustain the existing social relations and control systems. 
Smith's study can be seen to reflect a critical perspective as the focus is on the historical practices used by management to control the labor process. Underlying this focus is the assumption of conflict between labor and management, which it is believed is played out on the shop or office floor through the deployment of control systems and technologies. Additionally, Smith's work acknowledges the importance of history in shaping events. He examines the history of management control systems and work practices in the firms, and investigates the extent to which these institutionalized forms shape the deployment of technology in the work process. Finally, Smith explores the subtle control mechanisms (beyond those evident in the EPOS systems) that over time have become so embedded in worklife that they are no longer observable or discernable by the workers or managers.

\section{Critical Research Philosophy: Assessment}

The critical research perspective offers many new insights beyond those of the positivist and interpretive perspectives. It alerts us to the reality of interdependence of parts with the whole, and that organizations cannot be studied in isolation of the industry, society, and nation within which they operate, and which they in part constitute. Likewise, we are alerted to the central influence of historical, economic, social, and political conditions for the nature and development of phenomena. And finally, this perspective reminds us of the constantly changing potential of humans who need not be defined by their immediate circumstances. The status quo is merely one moment along an evolving and emergent dynamic of social reality.

We believe that all three of the research philosophies we have discussed above can offer an insightful perspective on the phenomena of interest in behavioral information systems research. What is required is that researchers understand the implications of their research perspective choice, and act in ways that reflect that knowledge.

\section{CONCLUSION}

We have suggested that the positivist world view prevalent in information systems research may be limiting the kinds of knowledge we are gaining about information systems phenomena, and influencing the way researchers and practitioners act towards these phenomena. We suggest that given the nature and complexity of the phenomena investigated by behavioral information systems researchers, a plurality of research paradigms would better to serve to inform our research endeavors. That is, rather than having to compromise and use what may be unworkable positivistic assumptions, a more appropriate stance may be to adopt a different philosophical approach whose premises are more suited to the research intention. To paraphrase Morgan 
[1983:385], the more we recognize that information processing is a social practice that impacts on a social world, the less appropriate the positivist approach becomes. This view is echoed in Galliers \& Land's [1987] as well as Weick's [1984] assessment of information systems research activity, in which they encourage information systems researchers to examine the role of a priori assumptions in their theoretical and methodological choices. Weick writes [1984:129] "The question of the appropriate methodology for studying technology impact is woven into issues of theoretical substance much more tightly than people might realize - or prefer. What people 'see' when they use various methods is largely a function of their prior beliefs or what they expect to find. Researchers in information systems usually expect to see rational systems, and they usually find them. What they fail to see is that additional processes and variables affecting technology impact lie outside their rational combination." Weick concludes by noting that a broader methodological approach to information systems research "... especially when the issues in technology and organizations are at a formative stage ... is much more likely to help MIS researchers see their subject more accurately" [1984:129].

Finally, we must clearly state that it is not our intention to replace the positivist perspective with critical or interpretive ones. Rather, researchers should ensure that they adopt a perspective that is compatible with their own research interests and predispositions, while remaining open to the possibility of other assumptions and interests. They should understand and acknowledge the extent to which the perspective they adopt will focus their attention on some things and not others, and bias their perception of the phenomena they study. In this paper we have urged the adoption of non-positivist perspectives because these have been underrepresented in behavioral information systems research. However the issue of self-reflection about research perspective applies to every researcher whatever the perspective they adopt, whether interpretive, critical, or positivist. Morgan [1983:389-391] drawing on Gödel's theorem to emphasize that all theoretical formulations are necessarily incomplete [Gödel 1962], succinctly captures the message we have tried to convey here: “... all social phenomena may have many potential ways of revealing themselves and the way they are realized in practice depends on the mode of engagement adopted by the researcher. ... in choosing a research strategy the scientist in large measure determines how the phenomenon being studied will be revealed, and indirectly, the consequences of the knowledge thus generated." We hope that this paper has stimulated some reflection on the implications of the research approaches we employ when we investigate behavioral information systems phenomena, and that this may motivate a more reasoned, reflective adoption of the rich and diverse perspectives available to investigate the rich and diverse arena of information technology development and use in organizations. 


\section{REFERENCES}

Agar, Michael H. The Professional Stranger New York: Academic Press, 1980.

Alavi, Maryam \& Henderson, John C. "Evolutionary Strategy for Implementing a Decision Support System," Managment Science, November 1981, 1309-1323.

Astley, W. Graham "Adminstrative Science as Socially Constructed Truth," Adminstrative Science Quarterly, Vol.30, 1985: 497-513.

Astley, W. Graham \& Van de Ven, Andrew "Central Perspectives and Debates in Organization Theory," Administrative Science Quarterly, June 1983, 245-273.

Attewell, Paul \& Rule, James "Computing and Organizations: What We Know and What We Don't Know," Communications of the ACM, December 1984, 1184-1191.

Baroudi, Jack J. "The Impact of Role Variables on Information Systems Personnel Work Attitudes and Intentions," MIS Quarterly, December 1985, 341-365.

Bartol, Kathryn M. "Turnover among DP Personnel: A Causal Analysis," Communications of the ACM, October 1983, 807-811.

Benbasat, Izak "An Analysis of Research Methodologies," in F.Warren McFarlan ed. The Information Systems Research Challenge Harvard Business School Press: Boston, 1985, 4785.

Benbasat Izak, Goldstein David \& Mead Melissa "The Case Research Strategy in Studies of Information Systems," MIS Quarterly, Vol. 11, No. 3, 1987: 369-387.

Benson, J. Kenneth "Paradigm and Praxis in Organizational Analysis, Research in Organizational Behavior, Vol. 5, 1983: 33-56.

Berger, Peter \& Luckmann, Thomas The Social Construction of Reality Doubleday Books: New York, 1966.

Bernstein, Richard J. The Restructuring of Social and Political Theory University of Pennsylvania Press; Philadelphia PA, 1978.

Bernstein, Richard J. Beyond Objectivism and Relativism University of Pennsylvania Press; Philadelphia PA, 1985.

Bhaskar, Roy A Realist Theory of Science Brighton, UK: Harvester Press, 1978.

Bjørn-Anderson, N. \& Pederson, P.H. "Computer Facilitated Changes in the Management Power Structure," Accounting, Organizations and Society, Vol. 5, No. 2, 1980, 203-216.

Boland, Richard J. "The Process and Product of Systems Design," Management Science, 1978, 887-898.

Boland, Richard J. "Control, Causality and Information Systems Requirements," Accounting, Organizations and Society, Vol. 4, No. 4, 1979, 259-272. 
Boland, Richard J. "Phenomenology: A Preferred Approach to Research on Information Systems," in Mumford E., Hirschheim R., Fitzgerald G. \& Wood-Harper T. eds. Research Methods in Information Systems North-Holland: New York, 1985, 193-201.

Boland, R.J. \& Day, W. "The Phenomenology of Systems Design," in Procs. of the Third International Conference on Information Systems, Ann Arbor MI, December 1982.

Bostrom, R.P. \& Heinen, J.S. "MIS Problems and Failures: A Socio-Technical Perspective; Part I: The Causes", MIS Quarterly, September 1977a, 17-32.

Bostrom, R.P. \& Heinen, J. S. "MIS Problems and Failures: A Socio-Technical Perspective; Part II: The Application of Socio-Technical Theory", MIS Quarterly, December 1977b, 11-28.

Burrell, Gibson \& Morgan, Gareth Sociological Paradigms and Organization Analysis Heinemann Books: London, 1979.

Chua, Wai Fong "Radical Developments in Accounting Thought," The Accounting Review, LXI:4, October 1986: 601-632.

Culnan, Mary J. "The Intellectual Development of Management Information Systems, 19721982: A Co-citation Analysis." Management Science, February 1986, 156-172.

Culnan, Mary J. "Mapping the Intellectual Structure of Minformation systems, 1980-1985: A Co-citation Analysis," MIS Quarterly, September 1987, 341-353.

Culnan, Mary J. \& Swanson, E.B. "Research in Management Information Systems, 1980-1984: Points of Work and Reference," MIS Quarterly, September 1986, 289-302.

Culnan, Mary J. \& Markus, M.Lynne "Information Technologies," in Jablin, Frederic M. et al. eds. Handbook of Organizational Communication Newbury Park CA: Sage Publications; 1987: 420-443.

Daft, Richard L. \& Wiginton, John C. "Language and Organization," Academy of Management Review, Vol. 4, No. 2, 1979, 179-191.

Danziger, James N. et al. Computers and Politics: High Technology in American Local Government, Columbia University Press: New York, 1982.

Evered, Roger \& Louis, Meryl R. "Alternative Perspectives in the Organizational Sciences: Inquiry from the Inside and Inquiry from the Outside," Academy of Management Review, Vol. 6, No. 3, 1981, 385-395.

Fay, Brian "An Alternative View: Interpretive Social Science," in Gibbons, M.T. ed. Interpreting Politics New York: New York University Press; 1987: 82-100.

Franz, Charles R. \& Robey, "Daniel "An Investigation of User-led Systems Design: Rational and Political Perspectives", Communications of the ACM. December 1984.

Galliers, Robert D. \& Land, Frank F. "Choosing Appropriate Information Research Methodologies," Communications of the ACM, Vol. 30, No. 11, 1987, 900-902.

Gibbons, Michael T. "Introduction: the Politics of Interpretation," in Gibbons, M.T. ed. Interpreting Politics New York: New York University Press; 1987: 1-31. 
Giddens, Anthony Central Problems in Social Theory: Action. Structure and Contradiction in Social Analysis Berkeley CA: University of California Press, 1979.

Giddens, Anthony The Constitution of Society: Outline of the Theory of Structure Berkeley CA: University of California Press, 1984.

Giddens, Anthony Social Theory and Modern Sociology Stanford University Press: Stanford CA, 1987.

Ginzberg, Michael J. "Early Diagnosis of MIS Implementation Failure", Management Science, Vol. 27, No. 4, 1981, 459-478.

Glaser, Barney G. \& Strauss, Anselm The Discovery of Grounded Theory: Strategies for Qualitative Reserach Aldine Publishing: New York, 1967.

Gödel, Kurt On Formally Undecidable Propositions Basic Books: New York, 1962.

Hacking, Ian ed. Scientific Revolutions Oxford University Press: Oxford UK, 1981.

Hamilton, Scott \& Ives, Blake "MIS Research Strategies," Information \& Management, Vol. 5, 1982, 339-347.

Hirschheim, R., Klein, H. \& Newman, M. "A Social Action Perspective of Information System Development," Proceedings of the Eighth International Conference on Information Systems, Pittsburgh PA, December 1987: 45-56.

Ivancevich John, Napier Albert \& Wetherbe James "Occupational Stress, Attitudes, and Health Problems in the Information Systems Professional", Communications of the ACM, October 1983: 800-806.

Kaplan, Bonnie \& Duchon, Dennis "Combining Qualitative and Quantitative Methods in Information Systems Research: A Case Study," MIS Quarterly, Vol.12:4; 1988: 571-588.

Keen, Peter G.W. "MIS Research: Reference Disciplines and a Cumulative Tradition," Procs. of the First International Conference on Information Systems, Philadelphia PA, Dec. 1980, 9-18.

Klein, Heinz K. \& Welke, Richard J. "Information Systems as a Scientific Discipline," in Procs. of the Administrative Services Association of Canada Conference, University of Ottawa, Canada, Vol. 3, No. 4, 1982, 106-116.

Kling, Rob "Automated Welfare Client Tracking and Services Integration," Communications of the ACM, June 1978, 484-493.

Kling, Rob "Social Analyses of Computing: Theoretical Perspectives in Recent Empirical Research," Computing Surveys, March 1980, 61-110.

Kling, Rob \& Iacono, Suzanne "The Control of Information Systems Developments After Implementation," Communications of the ACM, December 1984, 1218-1226.

Kling, Rob \& Scacchi, Walter "The Web of Computing: Computer Technology as Social Organization," Advances in Computers, Vol. 21, 1982, 1-90.

Kuhn, Thomas S. The Structure of Scientific Revolutions University of Chicago Press: Chicago, 1970. 
Laudon, Kenneth Computers and Bureaucratic Reform, Wiley, New York, 1974.

Lee, Allen S. "Integrating Positivist and Interpretive Approaches to Organizational Research," Working Paper, College of Business Administration, Northeastern University, Boston MA: April 1989.

Lincoln, Y.S. \& Guba, E.G. Naturalistic Inquiry Sage Publications: Beverly Hills CA, 1985.

Littler, Craig \& Salaman, Graeme "Bravermania and Beyond: Recent Theories of the Labour Process," Sociology, Vol. 16, 1982; 251-269.

Lucas, Henry C. Jr. Implementation: The Key to Successful Information Systems New York: Columbia University Press, 1981.

Lucas, Henry C. Jr. "Organizational Power and the Information Services Department: A Reexamination", Communications of the ACM, January 1984, 58-65.

Markus, M. Lynne "Power, Politics, and MIS Implementation", Communications of the ACM, June 1983, 430-444.

Markus, M. Lynne \& Bjorn-Anderson, N. "Power over Users: Its Exercise by System Professionals", Communications of the ACM, June 1987, 498-504.

Markus, M. L. \& Robey, D. "Information Technology and Organizational Change: Causal Structure in Theory and Research," Management Science, Vol. 34, 1988.

Morgan, Gareth "Paradigms, Metaphors and Puzzle-Solving in Organization Theory," Administrative Science Quarterly, Vol. 25, 1980, 605-622.

Morgan, Gareth Beyond Method Sage Publications: Beverly Hills CA, 1983.

Morgan, Gareth \& Smircich, Linda "The Case for Qualitative Research," Academy of Management Review, Vol. 5, No. 4, 1980, 491-500.

Mumford, Enid \& Weir, Mary Computer Systems in Work Design: The ETHICS Method, Halstead Press" New York, 1979.

Mumford Enid, Hirschheim Rudi, Fitzgerald Guy \& Wood-Harper Trevor eds. Research Methods in Information Systems North-Holland: New York, 1985.

Newman, Michael \& Sabherwal, Rajiv "A Process Model for the Control of Information System Development Projects," Proceedings of the Tenth International Conference on Information Systems, Boston MA, December 1989: 185-198.

Nissen, Hans-Erik "Acquiring Knowledge of Information Systems - Research in Methodological Quagmire," in Mumford Enid, Hirschheim Rudi, Fitzgerald Guy \& Wood-Harper Trevor eds. Research Methods in Information Systems North-Holland: New York, 1985, 39-52.

Ollman, Bertell Alienation New York: Cambridge University Press, 1976.

Olson, Margrethe H. \& Primps, Sophia B. "Working at Home with Computers: Work and NonWork Issues", Journal of Social Issues, Vol. 40, No. 3, 1984, 97-112. 
Orlikowski, Wanda J. "Division among the Ranks: The Social Implications of CASE tools for Systems Developers" Proceedings of the Tenth International Conference on Information Systems, Boston MA, December 1989: 199-210.

Pettigrew, A.M. "Contextualist Research and the Study of Organizational Change Processes," in Mumford E., Hirschheim R., Fitzgerald G. \& Wood-Harper T. eds. Research Methods in Information Systems, North-Holland: New York, 1985, 53-78.

Pfeffer, Jeffrey Organizations and Organization Theory Pitnam: Boston, 1982.

Poole, Marshall Scott \& DeSanctis, Gerardine "Use of Group Decision Support Systems as an Appropriation Process, Procs. of the Hawaii International Conference on Information Systems, Hawaii, January 1989: 149-157.

Putnam, Linda L. "The Interpretive Perspective: An Alternative to Functionalism," in Putnam, L.L. \& Pacanowsky, M.E. eds. Communication and Organization Beverly Hills CA; Sage Press: 1983, 31-54.

Rice, R.E. \& Associates eds. The New Media: Communication, Research and Technology Newbury Park CA: Sage Publications; 1984.

Rosen, Michael "Coming to Terms with the Field: Understanding and Doing Organizational Ethnography," Journal of Management Studies, in press.

Rosson, Mary Beth, Maass, Susanne, \& Kellogg, Wendy "The Designer as User: Building Requirements for Design Tools from Design Practice," Communications of the ACM, November 1988, Volume 31, Number 11, 1288-1298.

Rowan, John The Social Individual Davis-Poynter: London, 1973.

Ryan, Alan ed. The Philosophy of the Social Sciences Macmillan: New York, 1970.

Ryan, Alan ed. The Philosophy of Social Explanations Oxford University Press: Oxford UK, 1973.

Saunders, Carol S. \& Scamell, Richard W. "Organizational Power and the Information Services Department: A Reexamination", Communications of the ACM, February 1986, 142-147.

Smith, Steven "How Much Change at the Store? The Impact of New Technologies and Labour Processes on Managers and Staffs in Retail Distribution," in Knights, D. and Willmott, H. eds. New Technology and the Labour Process. MacMillan Press, London, 1988: 143-162.

Sproull, Lee S. \& Kiesler, Sara "Reducing Social Context Cues: Electronic Mail in Organizational Communication," Management Science, Vol. 32, 1986, 1492-1512.

Steffy, Brian D. \& Grimes, Andrew J. "A Critical Theory of Organization Science" Academy of Management Review, Vol. 11, No. 2, 1986; 322-336.

Suchman, Lucy A. "Office Procedure as Practical Action: Models of Work and System Design," ACM Transactions on Office Information Systems, October 1983: 320328.

Tomkins, Cyril \& Groves, Roger "The Everyday Accountant and Researching His Reality," Accounting, Organizations and Society, Vol. 8, No. 4, 1983: 361-374. 
Turner, Jon A. "Computer-Mediated Work: The Interplay between Technology and Structured Jobs", Communications of the ACM, December 1984, 1210-1217.

Van Maanen, John "The Fact of Fiction in Organizational Ethnography," Administrative Science Quarterly, December 1979, 530-550.

Van Maanen, John Tales of the Field University of Chicago Press: Chicago, 1988.

Weber, Max The Theory of Social and Economic Organization Glencoe IL: Free Press, 1947.

Weber, Ron "Toward a Theory of Artifacts: A Paradigmatic Base for Information Systems Research," Working Paper, University of Queensland, Australia, April 1984.

Webster, Jane \& Starbuck, William H. "Theory Building in Industrial and Organizational Psychology", in Cary L. Cooper \& Ivan T. Robertson eds. International Review of Industrial and Organizational Psychology, Vol. 3, Wiley: Chichester UK, 1988, 93-138.

Weick, Karl The Social Psychology of Organizing Reading, MA: Addison-Wesley, 1979.

Weick, Karl E. "Theoretical Assumptions and Research Methodology Selection," in F. Warren McFarlan ed. The Information Systems Research Challenge Harvard Business School Press: Boston, 1984, 111-132.

Weick, Karl E. "Systematic Observational Methods", in Gardner Lindzey \& Elliot Aronson eds. Handbook of Social Psychology: Volume I - Theory and Method Random House: New York, 1985, 567-634.

Weiss, M. "Effects of Work Stress and Social Support on Information Systems Managers", MIS Quarterly, March 1983, 29-44.

Wood, Stephen (ed.) The Degradation of Work? London: Hutchinson \& Company; 1982.

Zuboff, Shoshanna In the Age of the Smart Machine Basic Books: New York, 1988. 


\begin{tabular}{|l|c|c|}
\hline \multicolumn{1}{|c|}{ Journal } & Frequency & Percent \\
\hline Communications of the ACM & 56 & 36.1 \\
\hline MIS Quarterly & 49 & 31.6 \\
\hline Proceedings of ICIS & 43 & 27.7 \\
\hline Management Science & 7 & 4.6 \\
\hline & 155 & $100 \%$ \\
\hline
\end{tabular}

Figure 1: Articles per Journal

\begin{tabular}{|c|c|c|}
\hline $\begin{array}{c}\text { Research Category } \\
\text { [Culnan 1987] }\end{array}$ & Frequency & Percent \\
\hline $\begin{array}{l}\text { Individual Approaches } \\
\text { to MIS Design \& Use }\end{array}$ & 85 & 54.8 \\
\hline MIS Management & 36 & 23.3 \\
\hline $\begin{array}{l}\text { Organizational Approach } \\
\text { to MIS Design \& Use }\end{array}$ & 34 & 21.9 \\
\hline & 155 & $100 \%$ \\
\hline
\end{tabular}

Figure 2: Articles Classified by Research Category 


\begin{tabular}{|l|c|c|}
\hline Research Design & Frequency & Percent \\
\hline Survey & 76 & 49.1 \\
\hline Lab Experiment & 42 & 27.1 \\
\hline Case Study & 21 & 13.5 \\
\hline Mixed Method & 5 & 3.2 \\
\hline Field Experiment & 4 & 2.6 \\
\hline Instrument Development & 4 & 2.6 \\
\hline Protocol Analysis & 2 & 1.3 \\
\hline Action Research & 1 & 0.6 \\
\hline & 155 & $100 \%$ \\
\hline
\end{tabular}

Figure 3: Articles Classified by Research Design

\begin{tabular}{|l|c|c|}
\hline \multicolumn{1}{|c|}{ Time $\begin{array}{c}\text { Period of } \\
\text { Study }\end{array}$} & Frequency & Percent \\
\hline Cross-Sectional: single snapshot & 140 & 90.3 \\
\hline Longitudinal & 7 & 4.5 \\
\hline Cross-Sectional: multiple snapshots & 6 & 3.9 \\
\hline Protocol Analysis & 2 & 1.3 \\
\hline & 155 & $100 \%$ \\
\hline
\end{tabular}

Figure 4: Articles Classified by Time Period of Study 


\begin{tabular}{|l|c|c|}
\hline \multicolumn{1}{|c|}{ Epistemology } & Frequency & Percent \\
\hline Postivist & 150 & 96.8 \\
\hline Interpretive & 5 & 3.2 \\
\hline Critical & 0 & 0 \\
\hline & 155 & $100 \%$ \\
\hline
\end{tabular}

Figure 5: Articles Classified by Epistemology 


\section{BELIEFS ABOUT PHYSICAL AND SOCIAL REALITY}

Ontological

Human Intention and Rationality

Social Order/Conflict

BELIEFS ABOUT KNOWLEDGE

Epistemological

Methodological

BELIEFS ABOUT THE RELATIONSHIP BETWEEN THEORY AND PRACTICE

Figure 6: Beliefs Underlying the Conduct of Research 
Center for Digital Economy Research

Stern School of Business

Working Paper IS-90-04 